\title{
The EURODIAB studies on childhood diabetes 1988-1999
}

\author{
A. Green \\ Department of Epidemiology and Social Medicine, University of Aarhus, Århus, Denmark
}

The EURODIAB (EUROpe and DIABetes) research activities on the epidemiology and prevention of diabetes were established in 1988 as a European Community Concerted Action initative under the Fourth Medical and Health Research Programme [1, 2]. As part of the EURODIAB programme, a collaborative network was established to characterise the epidemiology and aetiopathogenesis of Type I (insulindependent) diabetes mellitus. These research activities, subsumed under EURODIAB Sub-area A, were subsequently continued as separate concerted actions under the acronyms EURODIAB ACE (Aetiological Contribution to Type I diabetes on an Epidemiological basis), 1992-1996, and EURODIAB TIGER (Type I Genetic Epidemiology Resource), 1996-1999.

EURODIAB research on childhood diabetes has been carried out through a network of partners, with a central co-ordinating office located in Odense, Denmark. The working modalities have comprised standardised procedures and protocols, collaboration with centralised laboratory facilities, workshops, site visits and meetings, newsletters as well as a series of grant programmes to facilitate research training and development.

The core activities involved establishing a network for the registration of newly diagnosed children with Type I diabetes in geographically well-defined regions within Europe. Starting with 26 partners in 1989, the network had 44 centres contributing fully or partly to the incidence registration by mid- 1999 . The corresponding population coverage represents about 30 million children and most European nations. This has allowed a characterisation of the geographical distribution of Type I diabetes as well as investigations into temporal trends in incidence [3-7].

Corresponding author for the EURODIAB TIGER network: Prof. G. Soltész, Faculty of Medicine, Department of Paediatrics, Pécs University, József A.u. 7, 7623 Pécs, Hungary
Within the framework of the network, partnerships, formed to address research in related areas, have produced new information on familial and genetic factors, clinical characteristics at disease onset and possible associations between childhood Type I diabetes and other diseases as well as insights and possible non-genetic determinants [8-16]. Numerous additional publications from the individual network partners, whose data and results have emerged partly through the collaboration, have appeared over the years.

This TIGER Supplement marks 10 years of the EURODIAB collaboration on Type I diabetes, a time when the series of contracts with the European Commission is also coming to an end. It contains new data and results from the study group as well as papers from individual network partners. It has been produced to illustrate the importance of applying epidemiological methodology in the continuous research efforts to unravel the causes and pathogenesis of Type I diabetes. The results testify to the potential that exists in Europe for this kind of research. The huge geographical variability in the distribution of the disease as well as the distinct features of trends in the incidence emerge from the accumulated data.

An epidemiological approach and the continued monitoring of the incidence of Type I diabetes in network activities like the EURODIAB ACE/TIGER collaboration offers great opportunities for progress in diabetes research. Over the years almost 30000 cases have been accumulated, representing an unparalleled resource for further research initiatives into the causes, clinical and public health aspects of Type I diabetes. We hope that this Supplement will stimulate such initiatives.

Acknowledgements. All participating research teams, their partners and patients are thanked for their continuous engagement over the years. So are all the colleagues who over the 
years have co-ordinated sub-study activities and served as steering committee members. The main support for co-ordination of research has been obtained from the European Community Concerted Action Programme (grants MR4*/029/UK, BMH1-CT92-0043 and BMH4-CT96-0577). Additional support has been obtained from The Danish Diabetes Association, the Danish Medical Research Council (grant no. 12-9100), Novo Nordisk A/S and the Novo Nordisk Foundation. The Co-ordinating Office has been affiliated to Odense University (1988-1996) and Odense University Hospital (1996-1999), with expert secretarial and administrative management by Ms. G. Brutti.

\section{References}

1. Fuller JH (1994) The epidemiology and prevention of diabetes. In: Vuylsteek K, Hallen M (eds) Epidemiology. IOS Press, Amsterdam, pp 140-167

2. Williams R, Papoz L, Fuller J (1994) Diabetes in Europe, John Libbey, Kent

3. Green A, Gale EAM, Patterson CC, The EURODIAB Subarea A Study Group (1992) Incidence of childhood-onset insulin-dependent diabetes mellitus: The EURODIAB ACE Study. Lancet 339: 905-909

4. Levy-Marchal C, Patterson CC, Green A, on behalf of the EURODIAB ACE Study group (1995) Variation in age distribution and seasonality at diagnosis of childhood IDDM in Europe. Diabetologia 38: 823-830

5. EURODIAB ACE Study Group (2001) Is childhood-onset Type I diabetes a wealth-related disease? An ecological analysis of European incidence rates. Diabetologia (This supplement) 44 [Suppl 3]: B 9-B 16

6. The EURODIAB ACE Study Group (2000) Variation and trends in incidence of childhood diabetes in Europe. Lancet 355: 873-876

7. EURODIAB TIGER Study Group (2001) Trends in the incidence of childhood-onset diabetes in Europe
1989-1998. Diabetologia (This Supplement) 44 [Suppl 3]: B 3-B 8

8. Soltész G, Dahlquist G, Patterson CC, on behalf of the EURODIAB ACE Study Group and the EURODIAB ACE Substudy 2 Group (1998) Familial Risk of Type I diabetes in European Children. Diabetologia 41: 1151-1156

9. Rønningen KS, Keiding N, Green A on behalf of Genomic Marker Contributors and the EURODIAB ACE Study Group (2001) Correlations between the incidence of childhood-onset Type I diabetes in Europe and HLA genotypes. Diabetologia (This Supplement) 44 [Suppl 3]: B 51-B 59

10. Levy-Marchal C, Patterson CC, Green A on behalf of the EURODIAB ACE Study Group (2001) Geographical variation of presentation at diagnosis of insulin-dependent (Type I) diabetes in children: The EURODIAB study. Diabetologia (This supplement) 44 [Suppl 3]: B 75-B 80

11. The EURODIAB Substudy 2 Study Group (1999) Vitamin D supplement in early childhood and risk for Type I (insulin-dependent) diabetes mellitus. Diabetologia 42: 51-54

12. The EURODIAB Substudy 2 Study Group (1999) Perinatal risk factors for childhood Type 1 diabetes in Europe. Diabetes Care 22: 1698-1702

13. The EURODIAB Substudy 2 Study Group (2000) Infections and vaccinations as risk factors for childhood Type I (insulin-dependent) diabetes mellitus: a multicentre casecontrol investigation. Diabetologia 43: 47-53

14. The EURODIAB Substudy 2 Study Group (2000) Decreased prevalence of atopic diseases in children with diabetes. J Pediatr 137: 470-474

15. Rothwell PM, Gutnikov SA, McKinney PA, Schober E, Ionescu-Tirgoviste C, Neu A for the European Diabetes Study Group (1999) Seasonality of birth in children with diabetes in Europe: multicentre cohort study. BMJ 319: 887-888

16. McKinney PA on behalf of the EURODIAB Seasonality of Birth Group (2001) Seasonality of birth in patients with childhood Type I diabetes in 19 European regions. Diabetologia (This Supplement) 44 [Suppl 3]: B 67-B 74 